\title{
PERSPECTIVE
}

\section{Malignant glaucoma and its management}

\author{
Simon Ruben, James Tsai, Roger Hitchings
}

Malignant glaucoma continues to present a difficult clinical challenge to the ophthalmologist. This probably reflects the fact that the exact mechanism behind its aetiology is still not clearly understood. This perspective presents an update on the management of malignant glaucoma in light of the results obtained at Moorfields Eye Hospital during the past 3 years and on reviewing the recent literature.

\section{Introduction}

The term malignant glaucoma was coined by Von Graefe in $1869 .{ }^{1} \mathrm{He}$ noted that following peripheral iridectomy for acute angle closure glaucoma a number of patients developed shallowing of the anterior chamber together with high intraocular pressure. The subsequent prognostic outlook for such eyes was typically poor, hence the term 'malignant'. This descriptive term remains appropriate today as the condition continues to be one of the most difficult types of secondary glaucoma to manage. Other terms have been used to describe the condition including cilio-lenticular block, ciliary block, and aqueous misdirection glaucoma. However, these terms are based on supposition relating to the underlying aetiology and until a better understanding of the pathomechanism of the condition is attained the term 'malignant glaucoma' expresses its seriousness and will continue to be used. Malignant glaucoma remains a condition with a poor outcome. At the outset diagnosis may be delayed and as a result there may be delay in administering optimal medical therapy. Many eyes do not respond to medical therapy and the surgical management remains difficult and controversial.

\section{Definition}

Classically, malignant glaucoma is characterised by a shallow anterior chamber associated with raised intraocular pressure and in the presence of a patent iridotomy. The condition usually follows intraocular surgery but has also been described following laser iridotomy ${ }^{2-5}$ and has even been associated with miotic therapy. ${ }^{6}$ Some authors lump together many different types of secondary glaucoma under the umbrella of malignant, including secondary pupil block and miscellaneous entities such as glaucoma associated with central retinal vein occlusion or following retinal detachment surgery. However, for the purposes of this article the more traditional definition is used which excludes these others.

\section{Pathophysiology}

\section{INCIDENCE}

Malignant glaucoma occurs in $2-4 \%$ of eyes undergoing surgery for angle closure glaucoma ${ }^{7}$ and may occur at any time following surgery, from the first postoperative day to many years later. Although first described as occurring after surgical peripheral iridectomy, the condition has been recognised after many different procedures. It may occur in phakic, pseudophakic, or aphakic eyes. ${ }^{8-10}$ It typically occurs following filtration surgery in eyes with angle closure but may also occur after cataract surgery ${ }^{10}$ or laser iridotomy. ${ }^{2-5}$ There have also been reports of the condition occurring following Nd-YAG cyclophotocoagulation, ${ }^{11}$ after laser sclerotomy, ${ }^{12}$ and of it being induced by the use of large optic intraocular lens. ${ }^{13}$

\section{MECHANISM}

The exact mechanism remains unclear. Shaffer proposed misdirection of aqueous either into or around the vitreous, although how this occurs is still not clear. ${ }^{14}$ There is likely to be an anatomical interaction between the ciliary processes, lens, and anterior vitreous face which causes the diversion of aqueous backwards into the vitreous cavity. This theory is backed up by the finding of anterior rotation of the ciliary body on ultrasound examination, and ciliary processes in direct contact with the lens equator. ${ }^{15}$ Furthermore, the anterior vitreous face may appose the posterior surface of the ciliary processes. Slit-lamp examination may reveal optically clear spaces within the vitreous which may be confirmed on ultrasound. The shallowing of the anterior chamber is associated with forward displacement of the lens-iris diaphragm. Whether this anterior movement allows a change in the anatomical configuration of the structures involved thus allowing diversion of aqueous posteriorly, or whether the increase volume of the aqueous causes this forward displacement, is not clear.

ULTRASOUND BIOMICROSCOPY

High frequency ultrasound biomicroscopy is a relatively new method that can be used to gain accurate real time images of anterior segment structures. It uses 50-100 $\mathrm{MHz}$ transducers incorporated into a B-mode clinical scanner. Higher frequency transducers are used for fine resolution viewing of superficial structures, while for deeper penetration lower frequency transducers are used with some loss of resolution. This technique has a depth of penetration of $4 \mathrm{~mm}$ and resolution of between 20 and 60 $\mu \mathrm{m} .{ }^{16}$ Using this method the configuration of anterior segment structures has been visualised during the malignant glaucoma process. This includes irido-corneal touch, appositional angle closure, and anterior rotation of the ciliary body with apposition to the iris. Thus, the relative positions of anterior segment structures in malignant glaucoma have been well visualised using high frequency ultrasound biomicroscopy, ${ }^{16}{ }^{17}$ and the images obtained support the accepted hypotheses regarding its pathogenesis including anterior rotation of the ciliary processes and forward displacement of the ciliary body and lens. However, while this instrument is of use in helping to clarify the mechanism of malignant glaucoma it has not yet been shown to be useful in management of the condition.

Whatever the true underlying mechanism, the fact that malignant glaucoma is relieved when a direct communication is made between the anterior chamber and vitreous cavity, supports the theory that the lens, anterior vitreous face, and ciliary processes are intimately involved. 


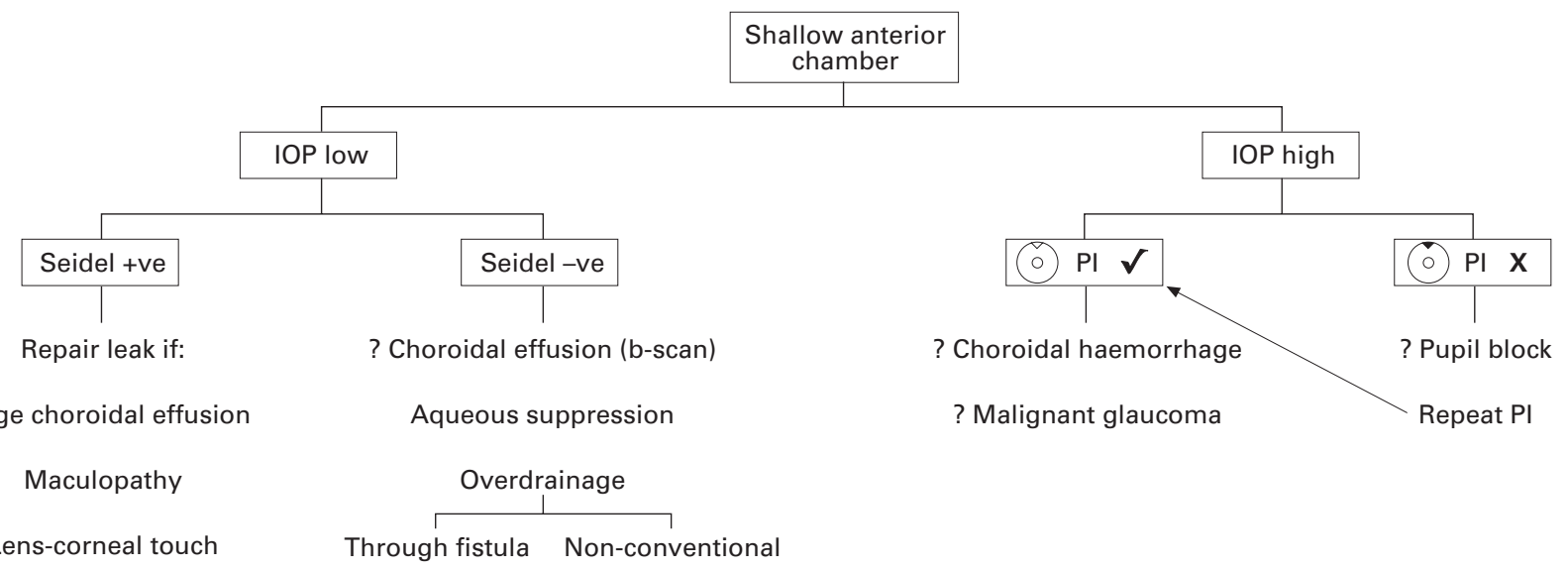

Figure 1 Algorithm showing management of a shallow anterior chamber following glaucoma drainage surgery. Note that in the early stages of malignant glaucoma the intraocular pressure may be normal.

\section{Diagnosis}

It is important to recognise the clinical signs of malignant glaucoma at an early stage in order to give the best chance of relieving the attack with medical treatment alone. Following filtration surgery malignant glaucoma presents as a shallow anterior chamber with normal or high intraocular pressure in the presence of a patent peripheral iridotomy. There is axial shallowing of the anterior chamber and, unlike pupil block, the iris is not typically bowed forwards. If the patency of the iridectomy is in doubt a repeat laser iridotomy can be performed to exclude pupil block. A shallow anterior chamber associated with a wound leak should be easily detectable and will usually be associated with hypotony. Hypotony without a wound leak may be associated with choroidal effusion or with excessive drainage into the subconjunctival space. If the iridotomy is patent and the intraocular pressure high choroidal haemorrhage must be excluded either clinically or by ultrasound examination. Figure 1 shows an algorithm that can be followed if there is a shallowing of the anterior chamber in the early postoperative period following glaucoma filtration surgery.

In the absence of a history of surgery other causes of secondary angle closure including intumescent lens, choroidal neoplasm, central retinal vein occlusion, ${ }^{18}$ and secondary pupil block must be excluded. ${ }^{7}$

\section{Management}

MEDICAL

Management is in the first instance medical. This consists of cycloplegic drops (and/or subconjunctival Mydricaine), topical $\beta$ blockers, aproclonidine, oral carbonic anhydrase inhibitors and, if necessary, oral glycerol or intravenous mannitol. Table 1 outlines the maximum medical therapy that can be administered. This combination shrinks the vitreous, decreases aqueous production, and encourages backward displacement of the lens-iris diaphragm. The exact combination of drugs will depend on the clinician's preference and where the patient is being treated. Fifty per cent of cases will be relieved within 5 days. ${ }^{15}$ If high pressure continues after this time, or if lens-corneal touch occurs, surgical intervention should be considered as prolonged shallowing of the anterior chamber will lead to the formation of peripheral anterior synechiae, posterior synechiae, cataract, and damage to the corneal endothelium.

Once the anterior chamber deepens and the intraocular pressure has been normalised, medical treatment can be gradually withdrawn. Hyperosmotic agents and carbonic anhydrase inhibitors are discontinued first followed by topical aproclonidine (if used) and $\beta$ blockers. The patient may be maintained on atropine alone, but may require indefinite treatment with atropine to prevent recurrence. One patient under our care has been managed for several years with the self administration of one drop of atropine once every 4-6 weeks as she is able to notice the refractive changes from anterior chamber shallowing that occur at an early stage.

\section{LASER}

Surgical intervention may take the form of laser or involve more invasive surgical procedures (see below). Direct argon laser through a peripheral iridectomy may be used in an attempt to shrink the ciliary processes and thus relieve cilio-lenticular block to anterior flow of aqueous. ${ }^{19}{ }^{20}$ Herschler ${ }^{19}$ reported success in five of six eyes treated in this manner. Alternatively, in aphakic or pseudophakic eyes, the Nd-YAG laser may be used to perform posterior capsulotomy/hyaloidotomy. ${ }^{21-25}$ This manoeuvre will only be effective if a direct communication between the vitreous cavity and anterior chamber can be established and, although encouraging results have been reported, it is often not easy to perform and may need several attempts. It has also been suggested that use of large optic $(7 \mathrm{~mm})$ posterior chamber lens implants may increase the risk of developing malignant glaucoma postoperatively and may

Table 1 Medical management of malignant glaucoma

\begin{tabular}{|c|c|}
\hline Drug & Dose \\
\hline \multicolumn{2}{|l|}{ For cycloplegia: } \\
\hline Atropine $1 \%$ & 6 times daily, reducing to maintenance dose \\
\hline Subconjunctival Mydricaine & \\
\hline \multicolumn{2}{|c|}{ For shrinkage of vitreous and/or reduction of aqueous production: } \\
\hline $\begin{array}{l}\beta \text { blocker } \\
\text {. }\end{array}$ & Twice daily (unless contraindicated) \\
\hline Aproclonidine $0.5 \%$ & Twice daily ( $1 \%$ initial Rx for IOP control) \\
\hline Acetazolamide & $250 \mathrm{mg}$ four times daily (consider guttae dorzolamide for maintenance) \\
\hline Glycerol ( $50 \%$ solution) & $0.5-1 \mathrm{ml} \mathrm{per} \mathrm{kg}$ twice daily \\
\hline Mannitol (intravenous) & $2 \mathrm{~g}$ per kg \\
\hline
\end{tabular}

Continue for $4-5$ days unless surgical intervention is necessary. 
also present an obstacle to successful hyaloidotomy as they may prevent adequate flow of aqueous from the vitreous into the anterior chamber. ${ }^{22}$ In the presence of synechiae between the lens capsule and implant such laser therapy may not prove successful. One way of improving the likely outcome of Nd-YAG laser therapy is to make the capsular opening through a dialling hole where present thus allowing a direct passage of aqueous between vitreous cavity and anterior chamber. ${ }^{26}$

\section{SURGERY}

In 1877 Weber described posterior sclerotomy performed 8-10 $\mathrm{mm}$ posterior to the limbus as a surgical treatment for malignant glaucoma. ${ }^{27}$ This probably succeeded because of vitreous loss through the wound. This technique was described again during the 1950s and 1960s combined with reformation of the anterior chamber with air. $^{7}$

Also during the latter part of the 19th century lens extraction was advocated. ${ }^{28} 29$ This technique again probably relied on inadvertent vitreous loss as its mechanism of action and this was noted in a series of six cases treated in this way by Chandler in $1950 .^{30}$ The malignant glaucoma persisted if vitreous was not lost. In 1954 Shaffer noted that lens extraction only relieved the malignant glaucoma if vitreous loss occurred or if the anterior hyaloid was deliberately incised ${ }^{14}$ and put forward the hypothesis that a direct communication between vitreous and anterior chamber was necessary for reversal of the malignant glaucoma process.

In 1964 Chandler described the technique of passing an 18 gauge needle back between the lens and ciliary processes into the vitreous to allow the escape of semifluid vitreous. $^{31}$ This technique was abandoned because of the high rate of cataract formation. In 1968 Chandler described the technique of vitreous aspiration through an 18 gauge needle via an incision $4 \mathrm{~mm}$ behind the limbus in conjunction with anterior chamber reformation with saline. ${ }^{32}$ This and similar techniques have remained in common use and with successful outcome in many eyes. ${ }^{15}$ However, this technique depends on the surgeon passing a needle $12 \mathrm{~mm}$ into the vitreous cavity in an almost blind manner and is not without its hazards. Because of this and because of improved microsurgical equipment and techniques, more recently pars plana vitrectomy, with or without lensectomy or extracapsular lens extraction, has been advocated for the surgical management of malignant glaucoma. In 1983 Momoeda reported successful reversal of malignant glaucoma in five eyes using anterior pars plana vitrectomy combined with intracapsular lens extraction through a corneal incision, although intraocular pressure required medical treatment in all five eyes and two required further filtration surgery. ${ }^{33}$ In 1981 Weiss et al reported a series of nine eyes successfully treated with vitrectomy. ${ }^{34}$ In 1986 Lynch et al described success with pars plana vitrectomy in four pseudophakic eyes. ${ }^{35}$ Of note was that in all cases with posterior chamber lenses excision of posterior capsule and zonules was included in the procedure thus creating a direct communication between vitreous cavity and anterior chamber. More recently Byrnes et al have reported on a series of 21 eyes (10 phakic and 11 pseudophakic) treated with vitrectomy. ${ }^{36}$ Of the phakic eyes only $50 \%$ had successful resolution of ciliary block compared with $90 \%$ in the pseudophakic group.

In a review of 21 eyes requiring surgical treatment at Moorfields Eye Hospital pars plana vitrectomy alone was successful in $67 \%(4 / 6)$ of pseudophakic but only $25 \%$ (1/4) of phakic eyes. Combined extracapsular cataract surgery combined with vitrectomy with intact posterior capsule had a success rate of $17 \%(1 / 6)$ whereas in patients in whom a primary posterior capsulotomy was performed the success rate was $83 \%(5 / 6)$. Two eyes underwent primary intracapsular cataract extraction with reversal of ciliary block although one subsequently required further filtration surgery.

Combined extracapsular cataract extraction and vitrectomy were performed by three different techniques: one patient underwent pars plana vitreo-lensectomy; two underwent extracapsular cataract extraction, posterior capsulotomy, and anterior vitrectomy; and three eyes underwent phacoemulsification, posterior capsulorrhexis, and vitrectomy. This technique is highlighted by the following case report.

\section{Case report}

A 41-year-old woman was referred by her optometrist with raised intraocular pressure. At presentation she had corrected visual acuities of $6 / 9$ each eye with $+4 \mathrm{D}$ correction. There was a right afferent pupillary defect. Intraocular pressures were $24 \mathrm{~mm} \mathrm{Hg}$ right and $44 \mathrm{~mm} \mathrm{Hg}$ left. Anterior chambers were shallow and gonioscopy revealed an open but narrow angle on the right but the left had $50 \%$ of the angle closed. Initial therapy consisted of Nd-YAG laser peripheral iridotomies with intraocular pressures of 16 and $19 \mathrm{~mm} \mathrm{Hg} 1$ week after laser and off all treatment. Six months later the intraocular pressures were $22 \mathrm{~mm} \mathrm{Hg}$ right and $40 \mathrm{~mm} \mathrm{Hg}$ left. Medical treatment with topical $\beta$ blocker and pilocarpine failed to adequately control intraocular pressure and she subsequently underwent left trabeculectomy. Preoperative ultrasound examination showed no abnormality in the ocular structures; in particular there was no enlargement or anterior rotation of the ciliary processes. Axial length was measured at $20.3 \mathrm{~mm}$.

The surgery was performed via a fornix based conjunctival flap. 5-Fluorouracil $(25 \mathrm{mg} / \mathrm{ml})$ was applied for 5 minutes subconjunctivally on a cellulose sponge followed by irrigation. A standard $4 \times 2 \mathrm{~mm}$ scleral flap was closed with two fixed and two releasable sutures and the anterior chamber was maintained with viscoelastic. On the first postoperative day the intraocular pressure was $16 \mathrm{~mm} \mathrm{Hg}$ and the anterior chamber deep. Over the following 10 days there was progressive shallowing of the anterior chamber and the intraocular pressure had risen to $26 \mathrm{~mm} \mathrm{Hg}$. At this point atropine was started. One week later the pressure was $36 \mathrm{~mm} \mathrm{Hg}$. After a single intravenous dose of acetazolamide the pressure fell to $18 \mathrm{~mm} \mathrm{Hg}$. Ultrasound at this stage showed normal posterior segment anatomy. During the following 3 months the intraocular pressure was maintained below $20 \mathrm{~mm} \mathrm{Hg}$ on atropine once daily. At this stage she developed a typical allergic response to the atropine drops which were discontinued. She represented soon after with pain and blurred vision. Examination showed anterior chamber shallowing with iridocorneal touch and intraocular pressure of $38 \mathrm{~mm} \mathrm{Hg}$. Medical treatment with hyoscine and acetazolamide resulted in resolution of the pressure but the anterior chamber remained shallow.

She underwent lens extraction combined with vitrectomy 4 weeks later. Phacoemulsification was performed through a superotemporal clear corneal incision. Posterior capsulotomy was performed with the Ocutome vitrector followed by anterior vitrectomy through the corneal incision. A $5 \times 6 \mathrm{~mm}$ optic posterior chamber lens was inserted in the capsular bag and the incision closed with a single $10 / 0$ nylon suture. On the fifth postoperative day visual acuity was $6 / 9$ unaided, intraocular pressure $14 \mathrm{~mm}$ $\mathrm{Hg}$, and the anterior chamber deep. It was noted that there was a significant amount of residual peripheral anterior synechiae. Despite resolution of the malignant glaucoma 
Table 2 Surgical management of chronic angle closure glaucoma

\begin{tabular}{|c|c|c|}
\hline Stage & Examination & Rationale \\
\hline 1 Preoperative assessment & $\begin{array}{l}\text { Indentation gonioscopy } \\
\text { Ultrasound B-scan } \\
\text { Ultrasound A-scan } \\
\text { Biomicroscopy }\end{array}$ & $\begin{array}{l}\text { Is there synechial closure of the angle? } \\
\text { Ciliary body/processes enlarged } \\
\text { Increased scleral thickness } \\
\text { Axial length-nanophthalmos } \\
\text { Lens opacity, ?extraction }\end{array}$ \\
\hline 2 Surgical technique & $\begin{array}{l}\text { ?Preoperative diode } \\
\text { Cyclophotocoagulation } \\
\text { Viscoelastic } \\
\text { Releasable sutures to scleral flap } \\
\text { (?consider lens extraction) }\end{array}$ & $\begin{array}{l}\text { Ciliary body shrinkage-allow time for this to occur } \\
\text { Postoperative maintenance of anterior chamber depth } \\
\text { (use paracentesis site for postoperative management) } \\
\text { Postoperative maintenance of anterior chamber depth }\end{array}$ \\
\hline 3 Postoperative & $\begin{array}{l}\text { Atropine } \\
\text { Viscoelastic }\end{array}$ & $\begin{array}{l}\text { Prevent forward displacement of lens-iris diaphragm } \\
\text { If anterior chamber reformation is necessary }\end{array}$ \\
\hline
\end{tabular}

the original trabeculectomy subsequently failed and she required further drainage surgery.

\section{COMMENT}

This case illustrates some of the important features and problems that may be encountered during the management of malignant glaucoma. Although eyes with malignant glaucoma may initially respond to medical management, long term cycloplegia is usually necessary to maintain resolution. Sensitisation to atropine drops is not uncommon and may occur at any time necessitating alternative treatment with hyoscine drops which may or may not be successful (or may not be available). Combined lens extraction and vitrectomy was considered to be the best surgical option in this patient despite mild lens opacity and previous best acuity of $6 / 9$, owing to the relatively large anteroposterior diameter of the lens, the associated peripheral anterior synechiae, and the poor results experienced by vitreous surgery alone. Phacoemulsification allows the surgery to be performed through a small incision with the maintenance of positive pressure within the eye thus minimising risk of choroidal effusion/haemorrhage. Anterior vitrectomy through a posterior capsulorrhexis allows provision for insertion of a posterior chamber lens as there may be inadequate stability of a small optic size lens if sulcus supported, and large optic lenses may block anterior flow of aqueous from the vitreous cavity and precipitate cilio-lenticular block. Failure of the original filtration surgery is likely to be a common complication and this may be prevented by adjunctive antimetabolite therapy, although repeat surgery may ultimately be necessary.

\section{Discussion}

Malignant glaucoma remains a most difficult clinical problem in terms of diagnosis and management. Early recognition and implementation of full medical treatment may enable us not to resort to difficult surgical measures. For this reason it is important, firstly, to be aware of those eyes at particular risk from developing malignant glaucoma and, secondly, to follow them closely in the early postoperative period (Table 2). Evaluation of the eye preoperatively should include careful indentation gonioscopy to determine whether there is synechial closure of the angle, particularly in eyes with long standing chronic angle closure treated

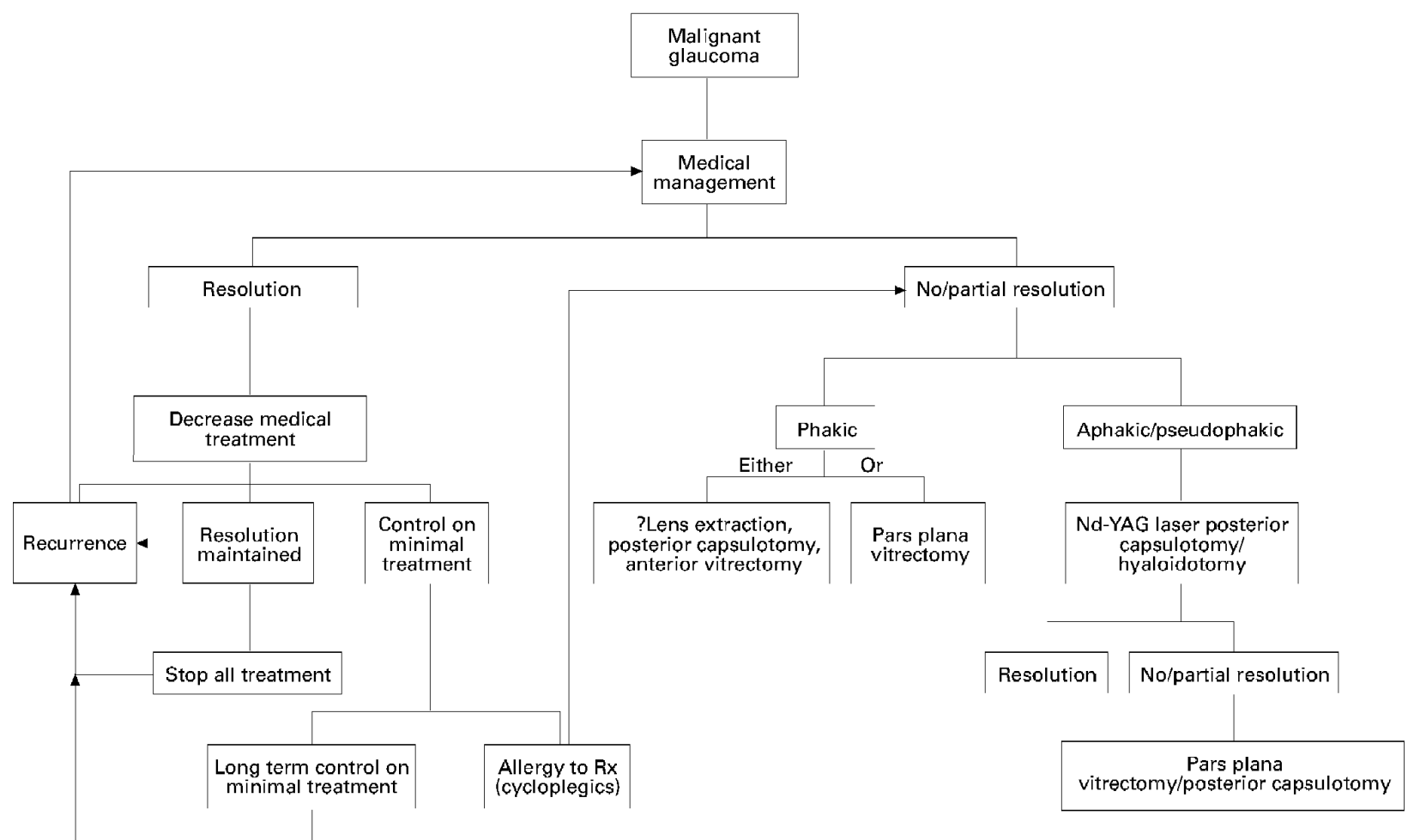

Figure 2 Algorithm summarising the management of malignant glaucoma (assuming diagnosis has already been made). Some eyes will need indefinite cycloplegic therapy. Surgery for phakic eyes is controversial. Lens extraction may be a difficult decision if there is no cataract and pars plana vitrectomy may be preferred as the first line treatment in this instance. 
with pilocarpine. Ultrasound examination to determine axial length and where possible to determine position and size of the ciliary body/processes should be performed. Filtration surgery can be modified to minimise the risks by use of releasable sutures to the scleral flap and the anterior chamber depth maintained in the immediate postoperative period by the use of viscoelastics during surgery. The aim of these modifications is to maintain the anatomical position of the lens-iris diaphragm and prevent misdirection of aqueous. Cycloplegia with atropine may also be employed but the argument against this is that should malignant glaucoma develop in an eye with a fully dilated pupil there is likely to be a far larger area of lens-corneal touch if anterior chamber shallowing occurs. In the case of chronic narrow angle glaucoma where there is an increase in the lens size which may still be compatible with good acuity, although often associated with myopic shift, lens extraction can also be considered as an option for the primary procedure either alone or combined with a filtration procedure. This is likely to reduce the risk of malignant glaucoma occurring but if it should surgical management in a pseudophakic eye is easier than in a phakic eye. Cyclophotocoagulation with the diode laser before trabeculectomy may also play a role in the management of chronic angle closure glaucoma as its use before surgery may help alleviate or prevent cilio-lenticular block by causing shrinkage of the ciliary body.

Should medical management fail to alleviate the attack a surgical option will become necessary. An eye with an already compromised optic nerve will not tolerate very high pressures for long periods and surgery should not be delayed if medical treatment fails to reverse the aqueous misdirection within 4-5 days. Where there is lens-corneal touch surgery should be performed within 24 hours. The flow chart in Figure 2 briefly outlines the steps taken in managing malignant glaucoma. Previous studies have shown that aphakic or pseudophakic eyes respond well either to initial YAG laser disruption of the posterior capsule/anterior hyaloid or, if this fails, pars plana vitrectomy is a safe and effective procedure in these eyes, taking care to take part of the posterior capsule in the pseudophakic eyes. Phakic eyes present more of a problem. Vitrectomy alone may not relieve the cilio-lenticular block because of the difficulty in adequately removing the anterior vitreous without at the same time damaging the lens. For this reason, if vitrectomy is successful it is likely to be accompanied by cataract formation. We would therefore recommend combined extracapsular cataract extraction/ phacoemulsification together with posterior capsulorrhexis and anterior vitrectomy in any patient with even mild lens opacity. In the presence of a clear lens, treatment is rather more controversial although clear lens extraction should certainly be considered and discussed with the patient.

\section{Conclusion}

The precise mechanism of malignant glaucoma remains unclear but it is almost certainly closely related to the anatomical relation between lens, zonules, anterior vitreous face, and ciliary body. Reversal of aqueous misdirection appears to be dependent on there being direct continuity between the vitreous cavity and anterior chamber which is difficult to achieve in the presence of a lens which is often relatively large. The management of this difficult condition is likely to remain controversial until the exact mechanism is more clearly understood. However, in the light of modern microsurgical techniques, reversal of ciliary block glaucoma can be achieved with preservation of good visual acuity and intraocular pressure control.

SIMON T RUBEN JAMES TSAI

ROGER A HITCHINGS

Glaucoma Department,

Moorfields Eye Hospital, London

1 von Graefe A. Beltrage zur pathologie und therapie des glaucomas. Albert von Graefe Arch Ophthalmol 1869;15:108.

Cashwell LF, Martin TJ. Malignant glaucoma after laser iridotomy. Ophthalmology 1992;99:651-8.

3 Robinson A, Prialnic M, Deutch D, Savir H. The onset of malignant glaucoma after prophylactic laser iridotomy. Am f Ophthalmol 1990;110:95-6.

4 Brooks AM, Harper CA, Gillies WE. Occurrence of malignant glaucoma after laser iridotomy. Br f Ophthalmol 1989;73:617-20.

5 Hodes BL. Malignant glaucoma after laser iridotomy. Ophthalmology 1992; 99:1641-2.

6 Rieser JC, Schwartz B. Miotic induced malignant glaucoma. Arch Ophthalmol 1972;87:706.

7 Luntz MH, Rosenblatt M. Malignant glaucoma. Surv Ophthalmol 1987;32: 73-93.

8 Reese AB. Herniation of the anterior hyaloid membrane following uncomplicated intracapsular cataract extraction. Am $尹$ Ophthalmol 1949;32:933-46.

9 Hanish SK, Lamberg RL, Gordon JM. Malignant glaucoma following cataract surgery and intraocular lens implant. Ophthalmic Surg 1982;13:713-4.

0 Duy TP, Wollensak J. Ciliary block (malignant) glaucoma followin posterior chamber lens implantation. Ophthalmic Surg 1987;18:741-4.

1 Hardten DR, Brown JD. Malignant glaucoma after Nd-YAG cyclophotocoagulation. Am $\mathcal{F}$ Ophthalmol 1991;111:245-7.

2 Cashwell LF, Martin TJ, Winston-Salem. Malignant glaucoma developing after laser sclerostomy. Ophthalmology 1991;98 (suppl):161.

13 Reed JE, Thomas JV, Lytle RA, Simmons RJ. Malignant glaucoma induced by an intraocular lens. Ophthalmic Surg 1990;21:177-80.

14 Shaffer RN. Role of vitreous detachment in aphakic and malignant glaucoma. Trans Am Acad Ophthalmol Otolaryngol 1954;58:217-31.

15 Simmons RJ, Thomas JV, Yaqub Malignant glaucoma. In: Ritch R, Shields MB, Krupin T, eds. The glaucomas. St Louis: CV Mosby, 1251-63.

16 Tello C, Chi T, Shepps G, Liebmann J, Ritch R. Ultrasound biomicroscope in pseudophakic malignant glaucoma. Ophthalmology 1993;100:1330-4.

17 Trope GE, Pavlin CJ, Bau A, Baumal CR, Foster FS. Malignant glaucoma. Clinical and ultrasound biomicroscopic features. Ophthalmology 1994;101: 1031-5.

18 Weber PA, Cohen JS, Baker ND. Central retinal vein occlusion and malignant glaucoma. Arch Ophthalmol 1987;105:635-6.

19 Herschler J. Laser shrinkage of the ciliary processes. A treatment for malignant (ciliary block) glaucoma. Ophthalmology 1980;87:1155-9.

20 Lee PF, Shihab Z, Eberle M. Partial ciliary process laser photocoagulation in the management of glaucoma. Lasers Surg Med 1980;1:85-92.

21 Epstein DL, Steiert RF, Puliafito CA. Neodymium-YAG laser therapy to the anterior hyaloid in aphakic malignant (ciliovitreal block) glaucoma. Am f Ophthalmol 1984;98:137-43.

22 Melamed S, Ashkenazi I, Blumenthal M. Nd-YAG laser hyaloidotomy for malignant glaucoma following one-piece $7 \mathrm{~mm}$ intraocular lens implantation. Br f Ophthalmol 1991;75:501-3.

23 Brown RH, Lynch MG, Tearse JE, Nunn RD. Neodymium-YAG vitreous surgery for phakic and pseudophakic malignant glaucoma. Arch Ophthalmol 1986;104:1464-6.

24 Halkias A, Magauran DM, Joyce M. Ciliary block (malignant) glaucoma after cataract extraction with lens implant treated with YAG laser capsulotomy and anterior hyaloidotomy. Br f Ophthalmol 1992;76:569-70. 25 Little B, Hitchings RA. Pseudophakic malignant glaucoma: Nd-YAG capsulotomy as primary treatment. Eye 1993;7:102-4

26 Risco JM, Tomey KF, Perkins TW. Laser capsulotomy through intraocular lens positioning holes in anterior aqueous misdirection. Case report. Arch Ophthalmol 1989;107:1569.

27 Weber A. Die Ursache des glaukoms. Arch Ophthalmol 1877;23:1.

28 Pagenstecher H. Uber Glaukoms. Arch Ophthalmol 1877;10:7.

29 Rheindorf O. Uber Glaukom. Klin Monatsbl Augenheilkd 1887;25: 148

30 Chandler PA. Malignant glaucoma. Trans Am Ophthalmol Soc 1950;48:12843.

31 Chandler PA. A new operation for malignant glaucoma: a preliminary report. Trans Am Ophthalmol Soc 1964;62:408-19.

32 ChandlerPA, Simmons RJ, Grant EM. Malignant glaucoma: medical and surgical treatment. Am $\mathcal{f}$ Ophthalmol 1968;66:495-502.

33 Momoeda S, Hayashi H, Oshima K. Anterior pars plana vitrectomy for phakic malignant glaucoma. fpn f Ophthalmol 1983;27:73-9.

34 Weiss H, Shin DH, Kollarits CR. Vitrectomy for malignant (ciliary block) glaucomas. Int Ophthalmol Clin 1981;21:113-9.

35 Lynch MG, Brown RH, Michels RG, Pollack IP, Stark WJ. Surgical vitrectomy for malignant glaucoma. Am f Ophthalmol 1986;102:149-53.

36 Byrnes GA, Leen MM, Wong TP, Benson WE. Vitrectomy for ciliary block (malignant) glaucoma. Ophthalmology 1995;102:1308-11. 